\title{
Assessment of the Effects of Heavy Metals in Soils after Removal by Nanoscale Zero-Valent Iron with Three Methods
}

\author{
Tianen Zhang ${ }^{1,2, \dagger}$, Bing Xia ${ }^{2,3,+}$, Yuanyuan Lu ${ }^{3,4}$, Xiaoyu Zhang ${ }^{3,4}$, Hongfeng Chen ${ }^{2}$, Rongrong Ying ${ }^{3,4, *}$ \\ and Shu Jin ${ }^{3, *}$ \\ 1 School of Resources and Environment, Anhui Agricultural University, Hefei 230036, China; ztebxf@163.com \\ 2 Research Academy of Environmental Sciences of Anhui Province, Hefei 230071, China; \\ sweetblues@gmail.com (B.X.); hongfeng.chen71@163.com (H.C.) \\ 3 Nanjing Institute of Environmental Sciences, MEE, Nanjing 210042, China; yylu@nies.org (Y.L.); \\ zhangxy8839@163.com (X.Z.) \\ 4 State Environmental Protection Key Laboratory of Soil Environmental Management and Pollution Control, \\ Nanjing 210042, China \\ * Correspondence: yrr@nies.org (R.Y.); 15147009441@163.com (S.J.) \\ $\dagger$ These authors contributed equally to this work.
}

check for updates

Citation: Zhang, T.; Xia, B.; Lu, Y.; Zhang, X.; Chen, H.; Ying, R.; Jin, S. Assessment of the Effects of Heavy Metals in Soils after Removal by Nanoscale Zero-Valent Iron with Three Methods. Sustainability 2022 14, 2273. https://doi.org/10.3390/ su14042273

Academic Editor: Mingxiang Zhang

Received: 16 December 2021

Accepted: 10 February 2022

Published: 17 February 2022

Publisher's Note: MDPI stays neutral with regard to jurisdictional claims in published maps and institutional affiliations.

Copyright: (C) 2022 by the authors. Licensee MDPI, Basel, Switzerland. This article is an open access article distributed under the terms and conditions of the Creative Commons Attribution (CC BY) license (https:// creativecommons.org/licenses/by/ $4.0 /)$.

\begin{abstract}
Nanoscale zero-valent iron (nZVI) has been broadly applied in the remediation of heavy metals pollution. In this research, the toxicity characteristic leaching procedure (TCLP), the in vitro gastrointestinal (IVG) method, and the diffusive gradients in thin-films (DGT) technique were used to evaluate the effects of heavy metals in soil with remediation by nZVI. The results indicate that, compared with the dose of $0.5 \mathrm{~g} \cdot \mathrm{L}^{-1}$, the $\mathrm{nZVI}$ in the dose of $1.0 \mathrm{~g} \cdot \mathrm{L}^{-1}$ can remove the heavy metals in the soil. The leaching toxicities of the heavy metals $(\mathrm{Cr}, \mathrm{Cu}, \mathrm{Zn}, \mathrm{Pb})$ showed apparent decreases after the remediation by nZVI. In the gastric phase, the highest bioaccessibility values of the $\mathrm{Cr}, \mathrm{Cu}$, $\mathrm{Zn}, \mathrm{Pb}$ were decreased by $27.2,31.7,11.7$, and $20.1 \%$, respectively. Moreover, in the gastric phase, the highest bioaccessibility values of the $\mathrm{Cr}, \mathrm{Cu}, \mathrm{Zn}, \mathrm{Pb}$ were decreased by 5.5, 1.29, 8.0, and 7.3\%, respectively. The availabilities of the heavy metals were also reduced. The above results show that the nZVI effectively reduced the heavy metal pollution in the soil.
\end{abstract}

Keywords: nZVI; heavy metal soil pollution; TCLP; IVG; DGT

\section{Introduction}

Soil is the material basis for human survival. With the development of industry and agriculture, and the application of the three main types of industrial wastes (municipal solid waste, and agricultural fertilizers and pesticides), large amounts of heavy metals are discharged into the environment [1]. Previous studies have shown that about 95\% of the pollutants produced in the world every year are discharged into the soil, and that the pollution of heavy metals in the soil is becoming more and more serious [2-4]. The pollution of heavy metals in soil is diverse. When heavy metals exist in the soil for a long time, they reduce the soil quality of the surrounding area [5]. If heavy metals invade the surface and enter the water area, they affect the global water environment, cause a serious waste of ecological resources, and destroy the balance of the natural ecosystem [6]. Whether the pollution is in industrial and mining wastelands, or in contaminated agricultural soil in relatively small amounts, it is often manifested as the compound pollution of multiple heavy metals [7]. The sources of heavy metal pollution are relatively complex. Heavy metals often enter the environment in the form of inorganic and organic mixtures, and they contain a variety of metals, which jointly produce a certain synergistic, or antagonistic, effect, and which have an impact on organisms and ecosystems. Heavy metals cannot be degraded by microorganisms; they can only undergo morphological transformation [8]. More complicated is that the various heavy metals that pollute the soil usually interact with 
each other, which creates difficulties in the application of heavy metal pollution controls and remediation technologies [9]. Engineering technology, physical chemistry, and biotechnology can be used to control heavy metal soil pollution. Among the many heavy metal treatment technologies, the stabilization technology for heavy metals is considered to be cost-effective and eco-friendly [10]. More and more attention has been paid and gradually applied to the remediation of heavy-metal-contaminated sites [11]. Among them, nanoscale zero-valent iron (nZVI) technology is regarded as a relatively powerful technology because of its simple operation process, high processing efficiency, low operating cost, low energy consumption, and the easy availability of the materials [12]. Potential soil stabilization remediation technologies have been successfully applied to the remediation of contaminated soil by many researchers [13].

The current assessment methods of the soil ecological risk mainly include the chemical leaching method, the biological method, and material structure characterization. Among them, the toxic extraction method (GB 5086.2-1997), the in vitro simulated extraction method (IVG), and the diffusive gradients in thin-films technique (DGT) have the advantages of accurate analysis results, simple operations, low costs, short experimental periods, and strong controllability. Many countries have gradually begun to use these methods in the risk assessment of heavy-metal-contaminated soil [13]. However, there are few reports on the ecological risk assessment of nZVI after soil restoration [14-16]. Therefore, the above three methods were used in this study to comprehensively investigate the leaching contents, bioavailabilities, and plant availabilities of contaminated heavy metals in soil after remediation with modified nZVI, so as to provide a basis for the site application of nZVI in the remediation of heavy metal pollution in soil.

\section{Materials and Methods}

\subsection{Collection and Analysis of Soil Samples}

The soil was collected from a high-pollution site $\left(113^{\circ} 45^{\prime} 23^{\prime \prime} \mathrm{N}, 25^{\circ} 0^{\prime} 36^{\prime \prime} \mathrm{E}\right)$ in Shaoguan, Guangdong Province, South China. After the soil sample is air-dried naturally, it is ground and passed through a 2-mm nylon sieve for use [17] (Table 1).

Table 1. Properties and heavy metal contents of the tested soils.

\begin{tabular}{cc}
\hline Main Physical and Chemical Properties & Testing Soil \\
\hline Particle size distribution $(\mathrm{mm})^{\mathrm{a}}$ & \\
$0.2-2.0(\%)$ & 33.1 \\
$0.02-0.2(\%)$ & 32.6 \\
$0.002-0.02(\%)$ & 28.4 \\
$<0.002(\%)$ & 5.9 \\
$\mathrm{pH}^{\mathrm{b}}$ & 5.32 \\
Soil organic matter $(\mathrm{g} / \mathrm{kg})$ & 31.6 \\
$\mathrm{CEC}(\mathrm{cmol} / \mathrm{kg})$ & 6.38 \\
$\mathrm{Zn}(\mathrm{mg} / \mathrm{kg})$ & 1830 \\
$\mathrm{~Pb}(\mathrm{mg} / \mathrm{kg})$ & 749 \\
$\mathrm{Cr}(\mathrm{mg} / \mathrm{kg})$ & 70.3 \\
$\mathrm{Cu}(\mathrm{mg} / \mathrm{kg})$ & 32.4 \\
\hline
\end{tabular}

Note: ${ }^{a}$ hydrometer method (TM-85 soil hydrometer); ${ }^{\mathrm{b}}$ liquid ratio: 2.5:1 (Sartorius PB-21 pH meter).

\subsection{Preparation of the $n Z V I$ Solution}

The nZVI used in the experiment was prepared by the liquid-phase reduction method [18]. At room temperature, with $\mathrm{N}_{2}$ protection conditions, a certain concentration of $\mathrm{FeSO}_{4} \cdot 7 \mathrm{H}_{2} \mathrm{O}$ solution (30\% absolute ethanol $+70 \%$ deionized water) was added to a $500-\mathrm{mL}$ three-necked flask, and then, under the condition of the molar ratio of $\mathrm{BH}_{4}{ }^{-} / \mathrm{Fe}^{2+}$ of 2.0 , the $\mathrm{NaBH}_{4}$ solution was added dropwise to the solution, at a speed of $2 \mathrm{~d} \cdot \mathrm{s}^{-1}$, and was then stirred quickly with a mechanical stirrer. After the reaction, the solution was centrifuged, and the supernatant was removed. The resulting black solid was washed with ethanol several 
times, and then the washed solid was vacuum-dried, ground, and placed in a brown bottle filled with $\mathrm{N}_{2}$. The basic principle of the reaction can be found in [19]:

$$
\mathrm{Fe}^{2+}+2 \mathrm{BH}_{4}{ }^{-}+6 \mathrm{H}_{2} \mathrm{O} \rightarrow \mathrm{Fe}^{0} \downarrow+2 \mathrm{~B}(\mathrm{OH})_{3}+7 \mathrm{H}_{2} \uparrow
$$

The prepared nZVI was analyzed by transmission electron microscopy (TEM) and a fully automatic surface area analyzer.

\subsection{Preparation of Standard Solution}

A certain mass of nZVI particles were weighed and dissolved in deionized water for $3 \mathrm{~min}$. Totals of $100 \mathrm{~g}$ of soil were put into three beakers, which are referred to as S1, S2, and S3. Then, the distilled water was added to the nZVI solution $\left(0.5 \mathrm{~g} \cdot \mathrm{L}^{-1}\right.$ and $1.0 \mathrm{~g} \cdot \mathrm{L}^{-1}$ of $\left.\mathrm{Fe}^{0}\right)$ in order to reach the maximum soil water-holding capacity. The solution was equilibrated for 14 days at room temperature, dried at $40{ }^{\circ} \mathrm{C}$ for $12 \mathrm{~h}$, ground, and was then stored in a sealed container.

\subsection{Assessment of the Effects of Heavy Metals}

\subsubsection{Removing the Heavy Metals by the Toxicity Leaching Method}

The leachate toxicities of the heavy metals were determined in accordance with, "Solid waste leaching toxicity leaching method: horizontal oscillation method" (GB 5086.2-1997), in order to evaluate the removal effect of the nZVI on the heavy metals [20]. Totals of $3.5 \mathrm{~g}$ each of Samples S1 and S2 were accurately weighed into 50-mL polyethylene bottles, the extract was added (distilled water, $\mathrm{pH}$ values between 5.8 and 6.3), according to the solid-to-liquid ratio of 1:10, and was fixed vertically on the shaker. The samples were then shaken at a speed of $110 \pm 10$ times/min at room temperature for $8 \mathrm{~h}$, and then passed through a filtration system equipped with a $0.45-\mu \mathrm{m}$ filter membrane, and then a vacuum pump was used to filter and collect the filtrate for testing. Three parallel samples were set up and a blank experiment was performed at the same time. The leaching toxicity of heavy metals is expressed by the leaching coefficient:

$$
\mathrm{LC}=\mathrm{TLO}_{\mathrm{b}} / \mathrm{LTO}_{\mathrm{a}} \times 100 \%
$$

where $\mathrm{LC}$ is the leaching coefficient; $\mathrm{TCO}_{\mathrm{b}}$ is the leaching toxicity of the heavy metals in the soil before stabilization; and $\mathrm{LTO}_{\mathrm{a}}$ is the leaching toxicity of the heavy metals in the soil after stabilization.

\subsubsection{Removing the Heavy Metals by the IVG (In Vitro Gastrointestinal) Method}

There were two main methods that are used to determine the effects of heavy metal remediation: experiment and simulation. In the traditional heavy metal experiment method, after the heavy metals enter the stomach through the mouth, they are further digested and absorbed in the intestinal tract. The ratio of the amounts of heavy metals to the total amount of heavy metals resolved in the stomach or intestines is called the "bioavailability" of soil heavy metals, and it represents the maximum absorption of soil heavy metals by animals or humans. As the in vitro method continues to mature, many countries have gradually applied these methods (especially in vitro digestion models) to the risk assessment of heavymetal-contaminated soils. The IVG method is a method that was proposed by Rodriguez in 1999 to predict the bioavailabilities of heavy metals in soil [21]. This experiment uses the IVG method to analyze the bioavailabilities of heavy metals in soil after ZVI remediation in order to evaluate the effect of remediating heavy metal pollution.

The simulation experiment refers to the in vitro experiment evaluation method, as described by Yin in [22]. The experiment sets three parallel samples and performs a blank experiment at the same time, which is mainly divided into two stages:

(1) A total of $1.0 \mathrm{~g}$ of soil sample was weighed and passed through a 60-mesh sieve. The soil sample was put into a 300-mL-tall glass beaker, and then $150 \mathrm{~mL}$ of gastric simulant solution and a few drops of silica emulsion were added. The solution adjusted the $\mathrm{pH}$ to 
1.8 with concentrated hydrochloric acid and when placed in water at $37^{\circ} \mathrm{C}$. The solution was then shacked for one hour and a reaction solution of $20 \mathrm{~mL}$ was injected. It was then centrifuged at $5000 \mathrm{rpm}$ for $20 \mathrm{~min}$. The remaining liquid was filtered with a filter membrane of $0.45 \mu \mathrm{m}$ and was then stored at $4{ }^{\circ} \mathrm{C}$ for testing.

(2) A total of $20 \mathrm{~mL}$ of new gastric juice and a few drops of silica emulsion were added in the beaker. The solution adjusted the $\mathrm{pH}$ to 5.5 with a $\mathrm{NaHCO}_{3}$-saturated solution. Totals of $0.0525 \mathrm{~g}$ of pancreatic salt and $0.525 \mathrm{~g}$ of bile salt were added, and the solution was shanked for one hour, injected with a reaction solution of $20 \mathrm{~mL}$, and then centrifuged at $5000 \mathrm{rpm}$ for $20 \mathrm{~min}$. The remaining liquid was filtered, with a filter membrane of $0.45 \mu \mathrm{m}$, and was stored at $4{ }^{\circ} \mathrm{C}$ for testing. The formula for calculating the bioavailability of heavy metals in soil samples is as follows:

$$
\text { Bioavailability }(\%)=\left(\mathrm{C}_{\mathrm{IV}} \cdot \mathrm{V}_{\mathrm{IV}}\right) /(\mathrm{Cs} \cdot \mathrm{Ms}) \times 100 \%
$$

where $\mathrm{C}_{\mathrm{IV}}$ is the total amount of specific soluble heavy metals $\left(\mathrm{mg} \cdot \mathrm{L}^{-1}\right)$ in the reaction liquid in the stomach or small-intestine phases of the in vitro test; $V_{I V}$ is the volume of the reaction liquid in the reactor $(\mathrm{L})$; Cs is the specific heavy metals in the soil content $\left(\mathrm{mg} \cdot \mathrm{kg}^{-1}\right)$; and Ms is the weight of the soil sample added to the reactor $(\mathrm{kg})$.

\subsubsection{Removing the Heavy Metals by the DGT (Diffusive Gradients in Thin-Films) Extraction Method}

Gradient film diffusion technology (DGT) is a new method for the in situ collection and measurement of the availability, or bioavailability, states of heavy metals that can be used to characterize the phytoavailability of heavy metals in contaminated soil [23,24]. The rapid adsorption of the DGT will lead to a decrease in the content of heavy metals in the solution between the DGT and the soil. This promotes the release of particulate heavy metals in the soil to replenish the soil solution. The measured effective heavy metals include the free and unstable, which are released from the soil solution and the surface of the soil particulate matter. The determination results not only reflect the static process between the soil particles and the soil solution, but also include the dynamic process of the soil solid-phase release to replenish the soil solution [25]. The absorption of heavy metals by plants under natural conditions is a complicated process, which is mainly controlled by diffusion. Therefore, the DGT method can better simulate and evaluate the process of the plant uptake of heavy metals in the soil.

This experiment refers to the method of Song et al. for evaluating the $\mathrm{Cd}$ absorption by ryegrass using DGT technology. Three parallel samples were set up and a blank experiment was performed at the same time [26]. The main steps are as follows:

(1) A total of $50.0 \mathrm{~g}$ of soil sample is weighed and passed through a 2-mm sieve. The soil layer thickness is maintained to $1.5 \mathrm{~cm}$, water is added to ensure that the soil moisture content to be tested reaches $60 \%$ of the maximum field-water-holding capacity, and it is then stored at $25^{\circ} \mathrm{C}$ for $48 \mathrm{~h}$;

(2) Placement of DGT. After the DGT device is rinsed with pure water, the surface of the filter membrane of the DGT device is lightly smeared with a small amount of the soil to be tested, and then the device is carefully inserted into the soil to ensure that it is in good contact with the soil, and it is then covered to maintain the soil moisture content. The time and the room temperature are recorded at the same time;

(3) Recovery and extraction of DGT. After storage for $24 \mathrm{~h}$, the DGT device is quickly taken out, the surface is rinsed with pure water until it is clean, the DGT is disassembled, the fixed membrane is taken out and placed in a $1.5-\mathrm{mL}$ centrifuge tube, $1 \mathrm{~mL}$ of $1 \mathrm{~mol} \cdot \mathrm{L}^{-1}$ $\mathrm{HNO}_{3}$ is added, and it is shake for $24 \mathrm{~h}$ so that the binding phase is completely submerged, and then it is left for $24 \mathrm{~h}$ after dilution to be tested. The sample is diluted from the centrifuge tube and ICP-MS is used for the determination. According to the formula, the effective content of heavy metal plants in the soil is calculated. The formula is as follows:

$$
\mathrm{M}=\mathrm{C}_{\mathrm{e}}\left(\mathrm{V}_{\mathrm{HNO}}+\mathrm{V}_{\mathrm{gel}}\right) / \mathrm{f}_{\mathrm{e}}
$$


where $\mathrm{Ce}\left(\mathrm{ug} \cdot \mathrm{L}^{-1}\right)$ is the concentration of heavy metals in the $1 \mathrm{~mol} \cdot \mathrm{L}^{-1} \mathrm{HNO}_{3}$ solution; $\mathrm{VHNO}_{3}$ is the volume of the $1 \mathrm{~mol} \cdot \mathrm{L}^{-1} \mathrm{HNO}_{3}$ solution soaking the binding phase; $\mathrm{V}_{\text {gel }}$ is the volume of the binding phase, which is generally $0.15 \mathrm{~mL}$; and $\mathrm{f}_{\mathrm{e}}$ is the elution factor of each metal, which is generally 0.8 .

\section{Results and Discussion}

\subsection{Characterization of $n Z V I$}

\subsubsection{The Characterization of the nZVI Structure}

The nZVI was immersed in absolute ethanol, dispersed ultrasonically for $10 \mathrm{~min}$, and then scattered on a copper net to make an electron microscope sample. The shape and size of the nZVI were observed with a JEM-200CX TEM under the condition of an accelerating voltage of $200 \mathrm{KV}$. It can be seen from Figure 1 that the nZVI particles are spherical, with a particle size of about $100 \mathrm{~nm}$, and that they form a black agglomerated chain structure. Since nZVI particles have a smaller wavelength than visible light, they absorb light waves and become ideal black bodies, and because of the combined action of geomagnetism, the magnetostatic force between the small particles, and the surface tension [27], the particles are easy to agglomerate and so they look like clusters. This chain structure increases the three-dimensional space of the adsorption between the particles and effectively improves the adsorption performance of nZVI.

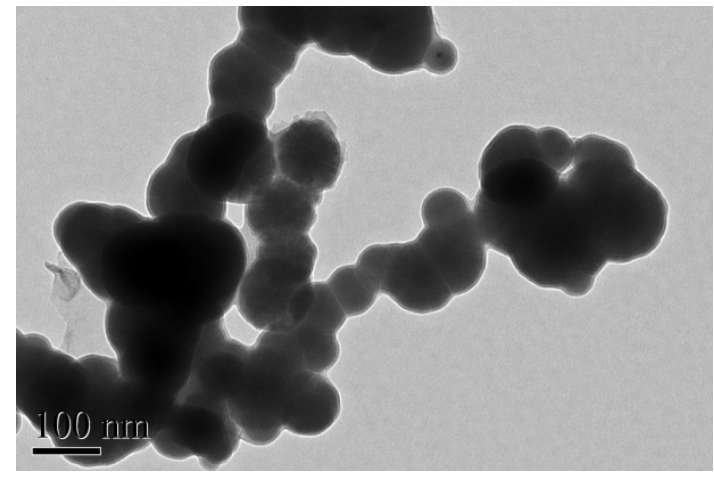

Figure 1. TEM image of nZVI.

\subsubsection{Specific Surface Area (BET) of nZVI}

The results show that the specific surface area of the nZVI particles prepared in this experiment is $21.56 \mathrm{~m}^{2} \cdot \mathrm{g}^{-1}$. From the BET surface area isotherm shown in Figure 2, it can be seen that when the $\mathrm{P} / \mathrm{P}_{\mathrm{o}}$ is between 0 and 0.3 , a small amount of $\mathrm{N}_{2}$ is adsorbed. The adsorption curve shown increases slowly, and then stabilizes. The adsorption amount increases rapidly, and the adsorption curve increases rapidly when the $\mathrm{P} / \mathrm{P}_{\mathrm{o}}$ reaches 0.7 , and desorption begins when the $\mathrm{P} / \mathrm{P}_{\mathrm{o}}$ reaches 1 . An adsorption/desorption hysteresis loop appears between a $\mathrm{P} / \mathrm{P}_{\mathrm{o}}$ of 0.7 and 1 , which shows a Type I curve, which is typical of microporous materials [28], and the nZVI has a certain adsorption capacity.

\subsection{The Leaching Effects of Heavy Metals on the Basis of the TCLP Method}

The experimental results are shown in Figure 3. It can be seen from the figure that, compared with the control, the leaching contents of the different heavy metals in the soil are reduced after 0.5 and $1 \mathrm{~g} \cdot \mathrm{L}^{-1}$ of nZNI. The nanoscale zero-valent iron (nZNI) is stabilized, and the leaching contents of the different heavy metals are different. This may be related to the initial contents and occurrences of the heavy metals [29]. The $\mathrm{Zn}$ had the highest leaching toxicities among S1, S2, and S3 at $71.34,56.2$, and $22.35 \mathrm{mg} \cdot \mathrm{L}^{-1}$, respectively. The $\mathrm{Cu}$ had the lowest toxicities, at 2.30, 1.23, and $0.182 \mathrm{mg} \cdot \mathrm{L}^{-1}$, respectively. According to the definition analysis of the leaching coefficient, after 0.5 and $1 \mathrm{~g} \cdot \mathrm{L}^{-1} \mathrm{nZNI}$ stabilizations, the leaching coefficients of the $\mathrm{Zn}$ are 78.8 and $31.3 \%$, respectively, and the leaching coefficients of the $\mathrm{Pb}$ are 53.5 and $12.0 \%$, respectively. The leaching coefficients of the $\mathrm{Cr}$ are 64.2 and 
$18.2 \%$, respectively, and the leaching coefficients of the $\mathrm{Cu}$ are 53.5 and $7.9 \%$, respectively. It can be seen that the stabilities of the heavy metals $(\mathrm{Zn}, \mathrm{Cr}, \mathrm{Pb}$, and $\mathrm{Cu})$ in the soil are improved after the nZNI is stabilized. The leaching toxicity of each heavy metal is reduced, which thereby reduces the ecological risk of the heavy metals in the soil. Compared with the treatment with $0.5 \mathrm{~g} / \mathrm{L}$ of Fe content, the heavy metal leaching content is reduced in the treatment with $1.0 \mathrm{~g} / \mathrm{L}$ of Fe content. This is because the $\mathrm{Fe}^{0}$ concentration increased with the active sites of the reaction, which increased the pollution on the surface of the fresh iron. The possibility of contact with the substance helps the reduction reaction of $\mathrm{Fe}^{0}$ [30]. Increasing the dosage is equivalent to increasing the surface area concentration of $\mathrm{Fe}^{0}$, and the greater the surface area concentration, the faster the reaction rate and the higher the pollutant removal rate [31-33].

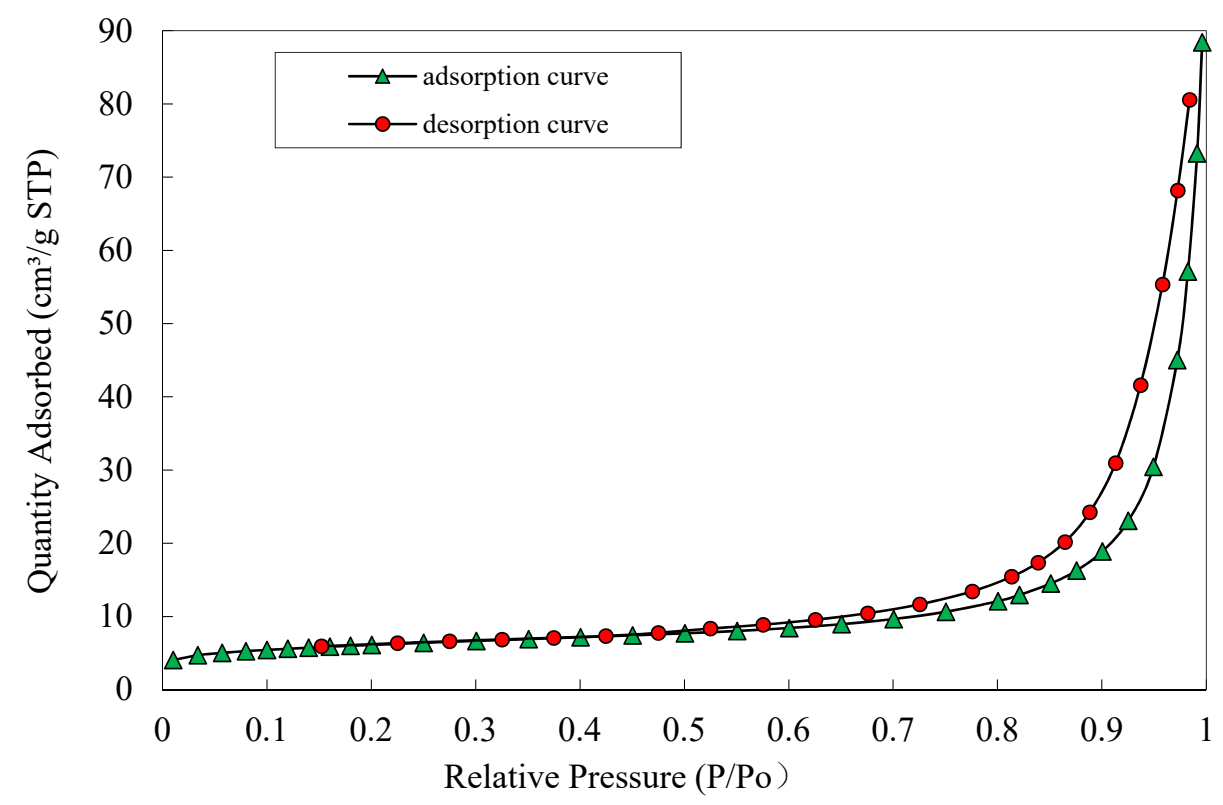

Figure 2. BET surface area isotherm of nZVI.

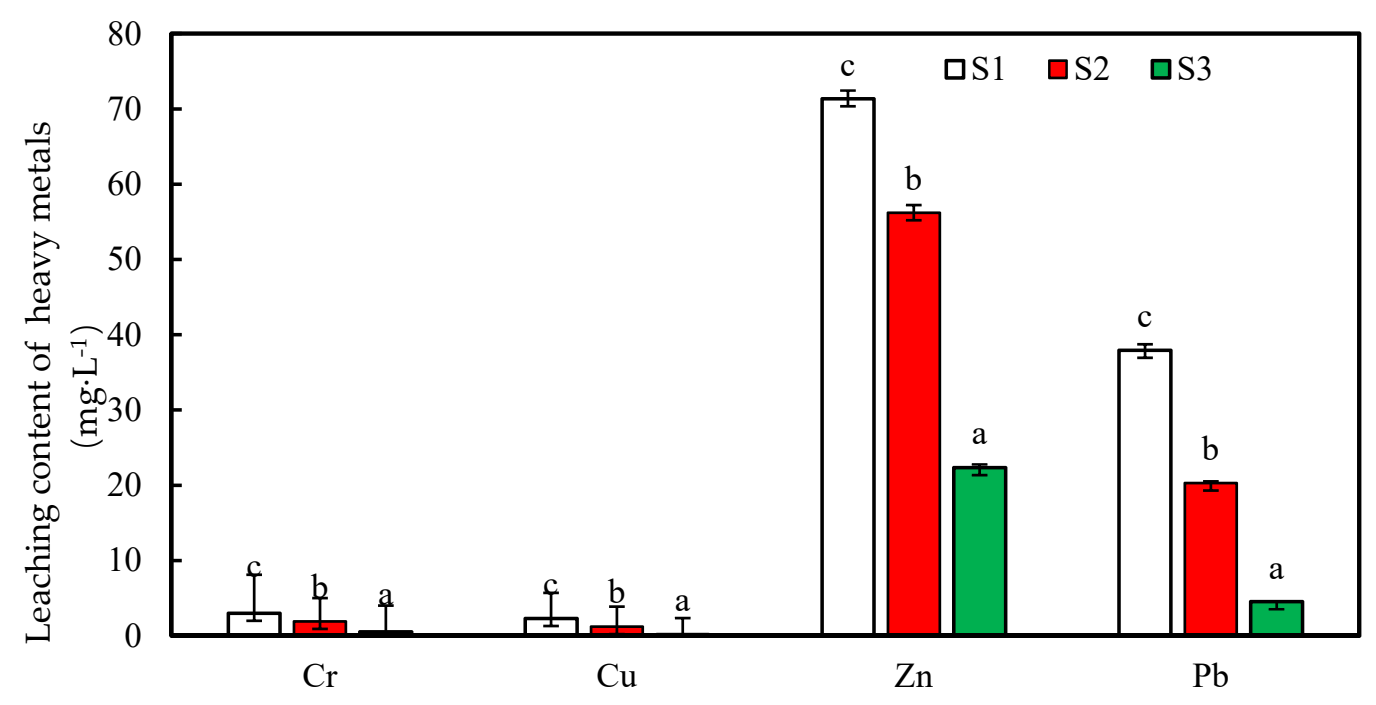

Figure 3. The leaching volumes of the $\mathrm{Cu}, \mathrm{Zn}, \mathrm{Pb}$, and $\mathrm{Cr}$ in the soil.

\subsection{The Leaching Effects of Heavy Metals on the Basis of the IVG Method}

The dissolved contents of the heavy metals in the stomach stage are shown in Figure 4. Compared with the control, after 0.5 and $1 \mathrm{~g} \cdot \mathrm{L}^{-1}$, the nZNI stabilized, and the contents of the heavy metals $(\mathrm{Cr}, \mathrm{Cu}$, and $\mathrm{Pb})$ in the soil in the stomach were reduced, while the 
$0.5 \mathrm{~g} \cdot \mathrm{L}^{-1} \mathrm{nZNI}$ showed no obvious stabilizing effect on the $\mathrm{Zn}$ in the soil. A total of $1.0 \mathrm{~g} \cdot \mathrm{L}^{-1}$ of nZNI can effectively reduce the $\mathrm{Zn}$ content in the soil. We further analyzed the bioavailability of each heavy metal in simulated gastric juice (Table 2), and the results show that, after 0.5 and $1 \mathrm{~g} \cdot \mathrm{L}^{-1}$, the $\mathrm{nZNI}$ was stabilized, the bioavailabilities of the $\mathrm{Cr}, \mathrm{Cu}, \mathrm{Zn}$, and $\mathrm{Pb}$ in the soil were $6.1,20.8,14.27$, and $48.24 \%$, respectively, and were decreased by $12.7,42.8,30.67$, and $72.1 \%$, respectively.

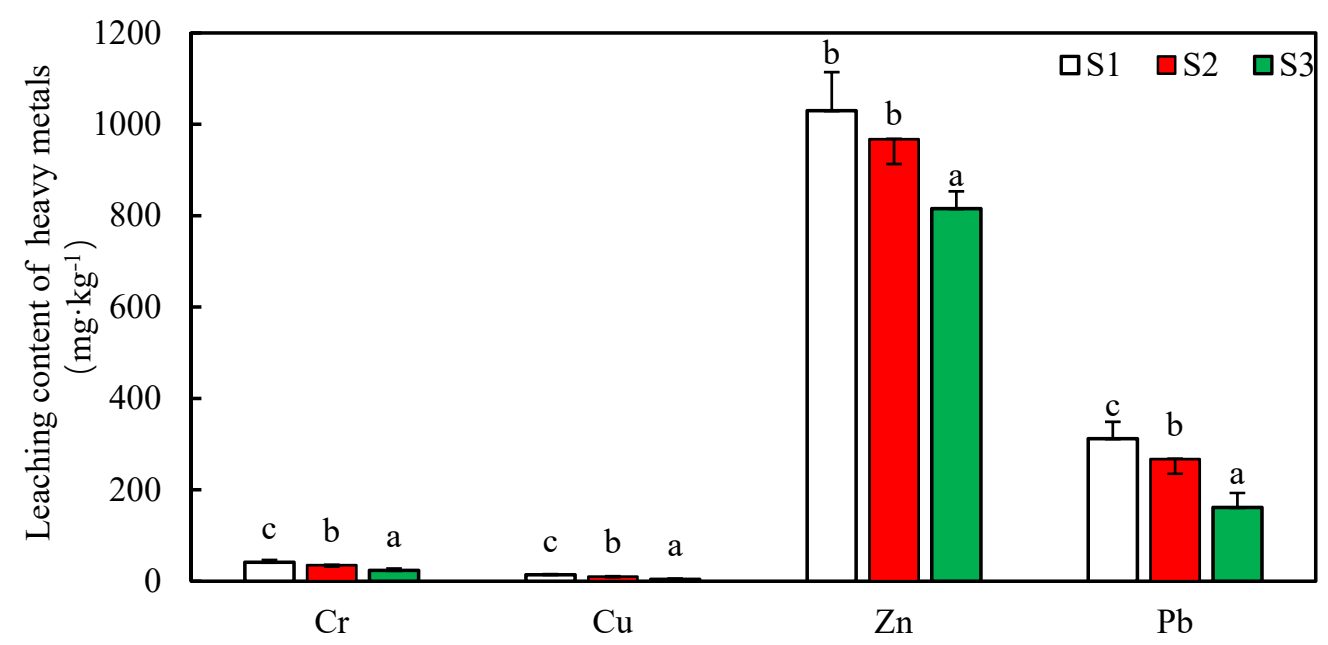

Figure 4. The soluble concentrations of the heavy metals $(\mathrm{Cu}, \mathrm{Zn}, \mathrm{Pb}, \mathrm{Cr})$ in the gastric phase.

The dissolved contents of the heavy metals in the small-intestine stage are shown in Figure 5. Compared with the control, after 0.5 and $1 \mathrm{~g} \cdot \mathrm{L}^{-1}$, the nZNI stabilized, and the contents of $\mathrm{Cr}, \mathrm{Cu}, \mathrm{Zn}$, and $\mathrm{Pb}$ in the stomach were decreased. We performed further analysis on the bioavailability of each heavy metal in the simulated gastric juice (Table 2), and the results show that after 0.5 and $1 \mathrm{~g} \cdot \mathrm{L}^{-1}$, the nZNI stabilized, the bioavailabilities of the $\mathrm{Cr}, \mathrm{Cu}, \mathrm{Zn}$, and $\mathrm{Pb}$ in the soil were $18.27,46.35,17.66$, and $36.22 \%$, respectively, and they decreased by $38.64,91.07,4.16$, and $13.54 \%$, respectively.

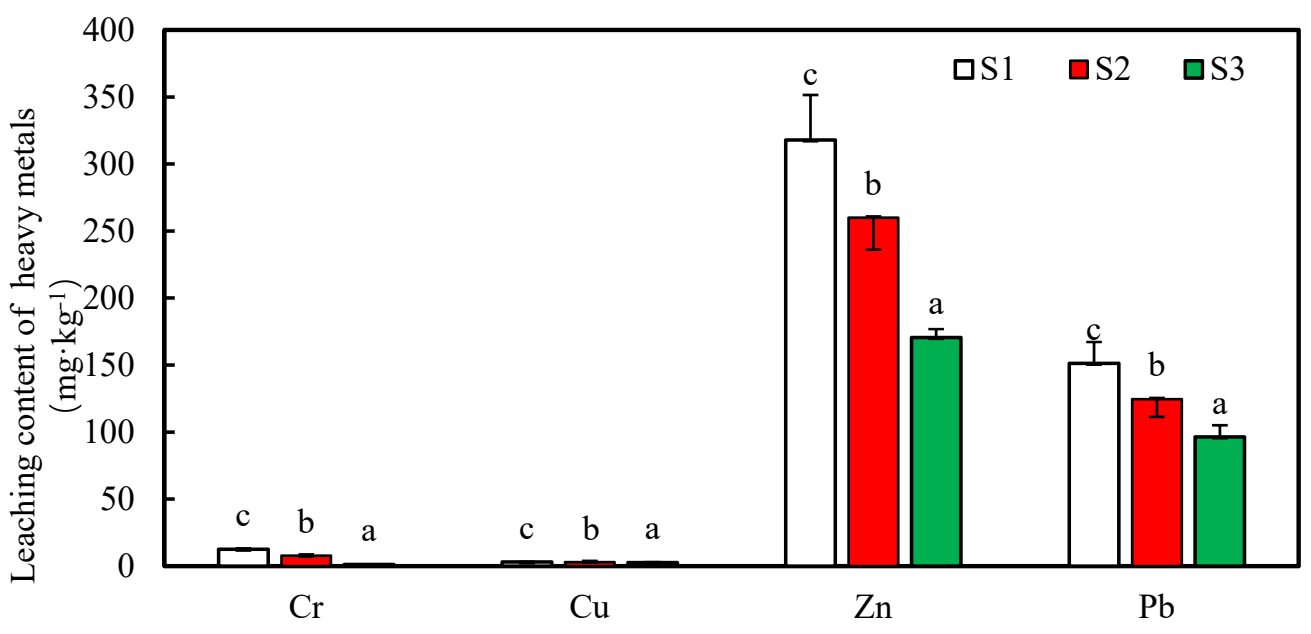

Figure 5. The soluble concentrations of the heavy metals $(\mathrm{Cu}, \mathrm{Zn}, \mathrm{Pb}, \mathrm{Cr})$ in the small-intestinal phase.

It can be seen from the results above that the availabilities of heavy metals in the stomach are higher than those in the small intestine. The main reason for this is that the $\mathrm{pH}$ in the stomach is lower than that in the small intestine. The availabilities of the heavy metals in the stomach of the soil samples (S2 and S3) are lower than those of the stable presoil (S1). This indicates that the nZNI had a certain stabilizing effect on the heavy metals in the soil. It not only greatly reduced the soluble states of the heavy metal contents, but 
also thereby reduced their bioavailabilities. Among them, the stabilizing effect of $1.0 \mathrm{~g} \cdot \mathrm{L}^{-1}$ of $\mathrm{nZNI}$ is higher than that of $0.5 \mathrm{~g} \cdot \mathrm{L}^{-1}$ of $\mathrm{nZNI}$.

Table 2. Bioaccessibilities of the heavy metals in gastric phase and small-intestinal phase (\%).

\begin{tabular}{cccccc}
\hline \multirow{2}{*}{$\begin{array}{c}\text { NZVI Potency } \\
\text { (g/L) }\end{array}$} & \multicolumn{4}{c}{ Lower Bioavailability (\%) } \\
\cline { 3 - 5 } & 0.5 & $\mathbf{C r}$ & $\mathbf{C u}$ & $\mathbf{Z n}$ & $\mathbf{P b}$ \\
\hline \multirow{2}{*}{ The stomach } & 1.0 & 12.70 & 30.71 & 6.12 & 14.27 \\
& 0.5 & 42.83 & 72.10 & 20.85 & 48.24 \\
Small intestine & 1.0 & 38.64 & 4.16 & 18.27 & 17.66 \\
& 91.07 & 13.54 & 46.35 & 36.22 \\
\hline
\end{tabular}

\subsection{The Leaching Effects of Heavy Metals on the Basis of the DGT Method}

The experimental results are shown in Table 3. It can be seen from the table that the contents of the heavy metals in the soil samples, S2 and S3, are reduced, and that the $\mathrm{Cr}$ and $\mathrm{Cu}$ in $\mathrm{S} 3$ are completely fixed by the nZNI. According to the definition of the phytoavailability of heavy metals, the concentration of heavy metals in the $1 \mathrm{~mol} \cdot \mathrm{L}^{-1} \mathrm{HNO}_{3}$ solution is positively correlated with the phytoavailability content. Compared with $\mathrm{S}$, the phytoavailability contents of the $\mathrm{Cr}, \mathrm{Cu}, \mathrm{Zn}$, and $\mathrm{Pb}$ are also greatly decreased for $\mathrm{S} 2$ and S3 because of the stronger adsorption capacities. This shows that nZNI stabilizes the heavy metals drifting in the soil and greatly reduces the amounts of heavy metals that can be absorbed by plants. Moreover, for various metals, the stabilizing effect of $1.0 \mathrm{~g} \cdot \mathrm{L}^{-1}$ of nZNI is greater than that of $0.5 \mathrm{~g} \cdot \mathrm{L}^{-1}$ of nZNI.

Table 3. The concentrations of the heavy metals in $1 \mathrm{~mol} \cdot \mathrm{L}^{-1} \mathrm{HNO}_{3}$ solution.

\begin{tabular}{ccccc}
\hline Soil Sample & $\mathbf{C r}$ & $\mathbf{C u}$ & $\mathbf{Z n}$ & $\mathbf{P b}$ \\
\hline $\mathrm{S} 1$ & $20.23 \pm 2.03 \mathrm{a}$ & $6.22 \pm 0.37 \mathrm{a}$ & $474.62 \pm 5.09 \mathrm{c}$ & $156.38 \pm 4.15 \mathrm{c}$ \\
$\mathrm{S} 2$ & $2.53 \pm 0.03 \mathrm{~b}$ & $3.74 \pm 0.20 \mathrm{~b}$ & $391.65 \pm 8.33 \mathrm{~b}$ & $31.28 \pm 2.06 \mathrm{~b}$ \\
$\mathrm{~S} 3$ & $/$ & $/$ & $253.03 \pm 10.21 \mathrm{a}$ & $8.39 \pm 0.34 \mathrm{a}$ \\
\hline
\end{tabular}

\section{Conclusions}

The leaching contents of the four heavy metals in the soil were reduced after 0.5 and $1 \mathrm{~g} \cdot \mathrm{L}^{-1}$ of the nZNI stabilized. The bioavailabilities of the $\mathrm{Cr}, \mathrm{Cu}, \mathrm{Zn}$, and $\mathrm{Pb}$ in the stomach decreased by 12.7 and $42.8 \%, 30.67$ and $72.1 \%, 6.1$ and $20.8 \%$, and 14.27 and $48.24 \%$ after 0.5 and $1 \mathrm{~g} \cdot \mathrm{L}^{-1}$ of the nZNI stabilized, respectively. Moreover, the bioavailabilities in the small intestine decreased by 38.64 and $91.07 \%, 4.16$ and $13.54 \%, 18.27$ and $46.35 \%$, and 17.66 and $36.22 \%$, respectively. The phytoavailabilities of the heavy metals in the soil decreased after 0.5 and $1.0 \mathrm{~g} \cdot \mathrm{L}^{-1}$ of nZNI-stabilized remediation. In summary, nZNI can be applied to effectively stabilize heavy metals in soil, thereby reducing the bioavailabilities and plant availabilities of the heavy metals in the soil, and subsequently reducing the toxic effects of heavy metals and their ecological risks in the soil.

Author Contributions: T.Z. and S.J. wrote the paper; B.X. conceived and designed the experiments; R.Y., Y.L. and X.Z. analyzed the data; and H.C. performed the experiments and collected the data. All authors have read and agreed to the published version of the manuscript.

Funding: This research was funded by the Natural Science Foundation of Anhui Province, grant number 2008085MD107.

Institutional Review Board Statement: Not applicable.

Informed Consent Statement: Not applicable.

Data Availability Statement: The data that support the findings of this study are available upon request from the authors.

Conflicts of Interest: The authors declare no conflict of interest. 


\section{References}

1. Spirenkova, O.V.; Bik, Y.I.; Roshchina, E.V.; Tushina, A.S.; Pridanova, O.V.; Kozenkova, G.L. Geoecological assessment of water bodies in novosibirsk using cluster methods. IOP Conf. Ser. Earth Environ. Sci. 2021, 867, 012050. [CrossRef]

2. Bezdicek, D.F.; Papendick, R.I.; Lal, R. Introduction: Importance of soil quality to health and sustainable land management. Methods Assess. Methods Assess. Soil Qual. 1996, 49, 1-8.

3. Bolan, N.; Kunhikrishnan, A.; Thangarajan, R.; Kumpiene, J.; Park, J.; Makino, T.; Kirkham, M.B.; Scheckel, K. Remediation of heavy metal(loid)s contaminated soils e to mobilize or to immobilize? J. Hazard Mater. 2014, 266, 141-166. [CrossRef]

4. Hang, X.S.; Wang, H.Y.; Zhou, J.M.; Ma, C.L.; Du, C.W.; Chen, X.Q. Risk assessment of portentially toxic element pollution in soils and rice (Oryza sativa) in a typical area of Yangtze River Delta. Environ. Pollut. 2009, 157, 2542-2549. [CrossRef] [PubMed]

5. Nicholson, F.A.; Smith, S.R.; Alloway, B.J. Quantifying heavy metal inputs to agricultural soils in England and Wales. Water Environ. J. 2006, 20, 87-95. [CrossRef]

6. Li, X.; Zhao, Z.; Ye, Y. Heavy metal accumulation and its spatial distribution in agricultural soils: Evidence from Hunan province, China. RSC Adv. 2018, 8, 10665-10672. [CrossRef]

7. McLaughlin, M.J.; Parker, D.R.; Clarke, J.M. Metals and micronutrients-food safety issues. Field Crops Res. 1999, 60, 143-163. [CrossRef]

8. Petraitis, E. Research into heavy metal concentrations in agricultural soils. Ekologija 2007, 15, 606-611.

9. Cui, Y.J.; Zhu, Y.G.; Zhai, R.H.; Huang, Y.Z.; Qiu, Y.; Liang, J.Z. Exposure to metal mixtures and human health impacts in a contaminated area in Nanning, China. Environ. Int. 2005, 31, 784-790. [CrossRef]

10. Marin, A.R.; Masscheleyn, P.H.; Patrick, W.H. Soil redox-pH stability of arsenic species and its influence on arsenic uptake by rice. Plant Soil 1993, 152, 245-253. [CrossRef]

11. Meharg, A.A.; Lombi, E.; Williams, P.N.; Scheckel, K.G.; Feldmann, J.; Raab, A.; Zhu, Y.G.; Islam, R. Speciation and localization of arsenic in white and brown rice grains. Environ. Sci. Technol. 2008, 42, 1051-1057. [CrossRef] [PubMed]

12. Rey, J.; Martinez, J.; Hidalgo, M.C.; Rojas, D. Heavy metal pollution in the Quaternary Garza basin: A multidisciplinary study of the environmental risks posed by mining (Linares, southern Spain). Catena 2013, 110, 234-242. [CrossRef]

13. Dudka, S.; Miller, W.P. Accumulation of potentially toxic elements in plants and their transfer to human food chain. J Environ. Sci. Health Part B-Pestic. Food Contam. Agric. Wastes 1999, 34, 681-708. [CrossRef] [PubMed]

14. Perrodin, Y.; Boillot, C.; Angerville, R.; Donguy, G.; Emmanuel, E. Ecological risk assessment of urban and industrial systems: A review. Sci. Total Environ. 2011, 409, 5162-5176. [CrossRef] [PubMed]

15. Suriyagoda, L.; Sirisena, D.; Somaweera, K.; Dissanayake, A.; De Costa, W.; Lambers, H. Incorporation of dolomite reduces iron toxicity, enhances growth and yield, and improves phosphorus and potassium nutrition in lowland rice (Oryza sativa L.). Plant Soil 2017, 410, 299-312. [CrossRef]

16. Mackie, K.A.; Müller, T.; Kandeler, E. Remediation of copper in vineyards-A mini review. Environ. Pollut. 2012, 167, 16-26. [CrossRef] [PubMed]

17. Krishna, A.K.; Govil, P.K. Soil contamination due to heavy metals from an industrial area of Surat, Gujarat, Western India. Environ. Monit. Assess. 2007, 124, 263-275. [CrossRef]

18. Chen, X.M.; Zhu, Y.C.; Fu, X.Y. Source and enrichment situation of heavy metals in apple orchard soils of Tianshui area, China. J. Agro-Environ. Sci. 2011, 30, 893-898.

19. Dahms, S.; Baker, N.J.; Greenfield, R. Ecological risk assessment of trace elements in sediment: A case study from Limpopo, South Africa. Ecotoxicol. Environ. Saf. 2017, 135, 106-114. [CrossRef]

20. Ren, H.L.; Cui, B.S.; Bai, J.H.; Dong, S.K.; Hu, B.; Zhao, H. Distribution of heavy metal in paddy soil of Hani Terrace core zone and assessment on its potential ecological risk. Acta Ecol. Sin. 2008, 28, 1625-1634.

21. Nicholson, F.; Smith, S.; Alloway, B.; Carlton-Smith, C.; Chambers, B. An inventory of heavy metals inputs to agricultural soils in England and Wales. Sci. Total Environ. 2003, 311, 205-219. [CrossRef]

22. Bangroo, S.; Najar, G.; Rasool, A. Effect of altitude and aspect on soil organic carbon and nitrogen stocks in the Himalayan Mawer Forest Range. Catena 2017, 158, 63-68. [CrossRef]

23. Kou, M.; Jiao, J.Y.; Yin, Q.L.; Wang, N.; Wang, Z.J.; Li, Y.J.; Yu, W.J.; Wei, Y.H.; Yan, F.C.; Cao, B.T. Successional trajectory over 10 years of vegetation restoration of abandoned slope croplands in the hill-gully region of the Loess Plateau. Land Degrad. Dev. 2016, 27, 919-932. [CrossRef]

24. Lucas, R.W.; Klaminder, J.; Futter, M.N.; Bishop, K.H.; Egnell, G.; Laudon, H.; Högberg, P. A meta-analysis of the effects of nitrogen additions on base cations: Implications for plants, soils, and streams. For. Ecol. Manag. 2011, 262, 95-104. [CrossRef]

25. Nguyen, V.B.; Nguyen, Q.B.; Zhang, Y.W.; Lim, C.Y.H.; Khoo, B.C. Effect of particle size on erosion characteristics. Wear 2016, 348-349, 126-137. [CrossRef]

26. Franzluebbers, A.J.; Haney, R.L.; Honeycutt, C.W.; Arshad, M.A.; Schomberg, H.H.; Hons, F.M. Climatic influences on active fractions of soil organic matter. Soil Biol. Biochem. 2001, 33, 1103-1111. [CrossRef]

27. Dawson, J.J.; Smith, P. Carbon losses from soil and its consequences for land-use management. Sci. Total Environ. 2007, 382, 165-190. [CrossRef]

28. Ghimire, P.; Bhatta, B.; Pokhrel, B.; Kafle, G.; Paudel, P. Soil organic carbon stocks under different land uses in Chure region of Makawanpur district, Nepal. SAARC J. Agric. 2019, 16, 13-23. [CrossRef] 
29. Reubens, B.; Achten, W.M.J.; Maes, W.H.; Danjon, F.; Aerts, R.; Poesen, J.; Muys, B. More than biofuel? Jatropha curcas root system symmetry and potential for soil erosion control. J. Arid Environ. 2011, 75, 201-205. [CrossRef]

30. Joshi, M.; Mer, G.S.; Singh, S.P.; Rawat, Y.S. Seasonal pattern of total soil respiration in undisturbed and disturbed ecosystems of Central Himalaya. Biol. Fert. Soils. 1991, 11, 267-272. [CrossRef]

31. Singh, S.; Ghoshal, N.; Singh, K.P. Variations in soil microbial biomass and crop roots due to differing resource quality inputs in a tropical dryland agroecosystem. Soil Biol. Biochem. 2007, 39, 76-86. [CrossRef]

32. Yilmaz, G. Seasonal variation of cumulative $\mathrm{CO}_{2}$ emission from a vertisol under apricot orchard in semi-arid southeast Turkey. Pedosphere 2012, 22, 322-332. [CrossRef]

33. Litton, C.M.; Ryan, M.G.; Knight, D.H.; Stahl, P.D. Soil-surface carbon dioxide efflux and microbial biomass in relation to tree density 13 years after a stand replacing fire in a lodgepole pine ecosystem. Glob. Chang. Biol. 2003, 9, 680-696. [CrossRef] 